\title{
Early dysregulation of trigeminal motor pool excitability in a mouse model for neurodegenerative motoneuron disease
}

\author{
Sharmila Venugopal ${ }^{1 *}$, Martina Wiedau-Pazos ${ }^{2}$, Scott H Chandler ${ }^{1}$ \\ From 24th Annual Computational Neuroscience Meeting: CNS*2015 \\ Prague, Czech Republic. 18-23 July 2015
}

Amyotrophic Lateral Sclerosis (ALS) is a progressive neurodegenerative motoneuron $(\mathrm{MN})$ where in fast fatigable motor units (MUs) of vulnerable motor pools preferentially degenerate followed by fast fatigue resistant and slow MUs . Excitability is a key endogenous mechanism of $\mathrm{MN}$ neuroprotection [1] and therefore we hypothesize that pre-symptomatic excitability indicates impending disease development. Using a transgenic mouse model for ALS, we performed in vitro patchclamp electrophysiology in ALS-vulnerable trigeminal motoneurons (TMNs) retrogradely labeled from jaw closer muscles at P8-12. We proposed a novel k-means clustering approach to classify TMNs into putative fast fatigable (PFF), fast fatigue resistant (PFR) and slow (PS) MUs based on rheobase and input resistance. Interestingly, hyper-excitability was noted in PFF and PFR

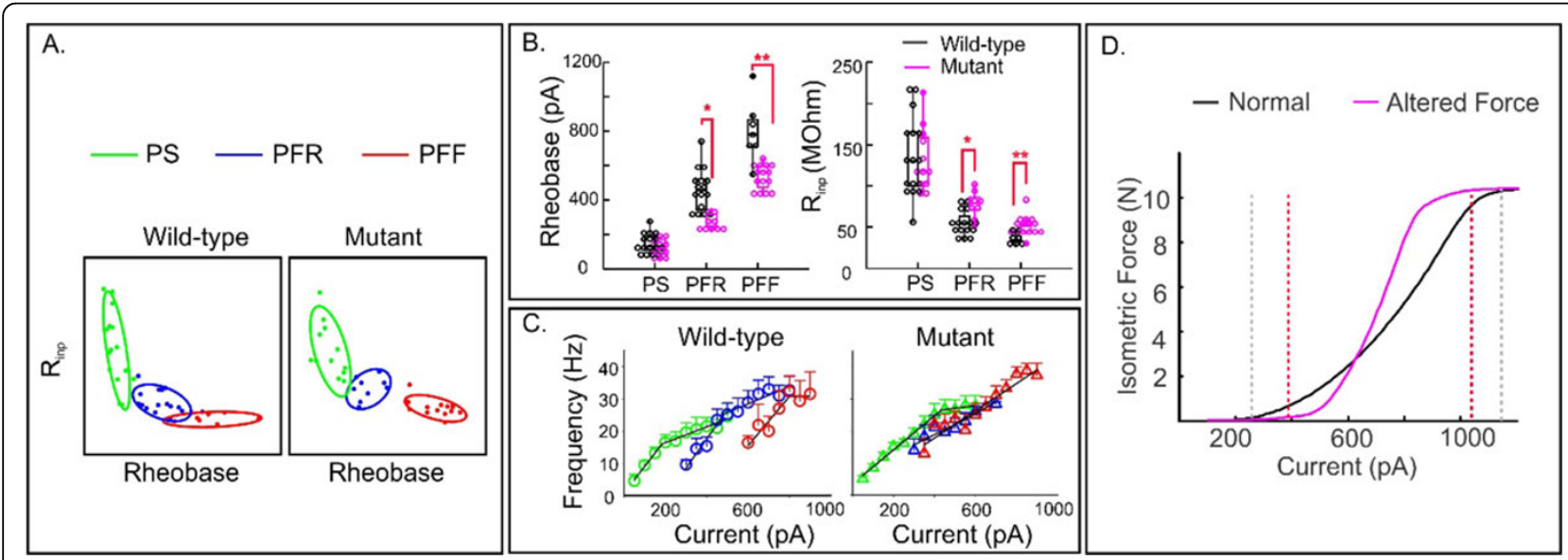

Figure $1 \mathrm{~A}$. Classification of TMNs into PFF, PFR and PS MU types using k-means clustering based on rheobase and input resistance $\left(\mathbf{R}_{\text {inp }}\right.$ ). B. Rheobase values were significantly lower among mutant PFR and PFF units compared with wild-type (Student's $t$ test, ${ }^{*} p=0.0002$ for $P F R,{ }^{* *} p=0.0001$ for PFF), whereas $R_{\text {inp }}$ values were significantly greater (Student's $t$ test, ${ }^{*} p=0.0009$ for PFR, ${ }^{* *} p=0.0028$ for PFF). Error bars indicate SD. C. F-I relationships of PS, PFR and PFF TMNs in wild-type and mutant mice; color coding is similar to $\mathbf{A}$. D. Simulation of isometric force versus MN input current across the jaw closer motor pool. Dashed lines demarcate normal (gray) and altered (red) muscle dynamic range.

\footnotetext{
* Correspondence: vsharmila@ucla.edu

'Department of Integrative Biology and Physiology, David Geffen School of

Medicine, University of California Los Angeles, Los Angeles, CA, USA

Full list of author information is available at the end of the article
} 
TMNs (Fig. 1B) while hypo-excitability was evident in a subset of PS TMNs with linear frequency-current (F-I) characteristics compared to wild-type TMNs [2]. The F-I relationships displayed dysregulation across the motor pool (Fig. 1C). A jaw closer motor pool model was developed and simulated in MATLAB ${ }^{\mathrm{TM}}$ using observed alterations in membrane properties amongst the mutant $\mathrm{MU}$ types. Model results predict resistance in muscle force initiation and reduced motor pool dynamic range due to opposite changes in excitability between slow and fast TMNs (Fig. 1D).

\section{Acknowledgements}

This study was supported by NIH grant NS071348 to S.H.C.

\section{Authors' details}

'Department of Integrative Biology and Physiology, David Geffen School of Medicine, University of California Los Angeles, Los Angeles, CA, USA.

${ }^{2}$ Department of Neurology, David Geffen School of Medicine, University of California Los Angeles, Los Angeles, CA, USA.

Published: 18 December 2015

\section{References}

1. Saxena S, Roselli F, Singh K, Leptien K, Julien JP, Gros-Louis F, et al: Neuroprotection through excitability and mTOR required in ALS motoneurons to delay disease and extend survival. Neuron 2013, 80(1):80-96.

2. Venugopal S, Hsiao C, Sonoda T, Weida-Pazos M, Chandler S: Homeostatic dysregulation in membrane properties of masticatory motoneurons compared to oculomotor neurons in a mouse model for Amyotrophic Lateral Sclerosis. Journal of Neuroscience 2015, 35(2):707-720.

doi:10.1186/1471-2202-16-S1-P31

Cite this article as: Venugopal et al.: Early dysregulation of trigeminal motor pool excitability in a mouse model for neurodegenerative motoneuron disease. BMC Neuroscience 2015 16(Suppl 1):P31.

\section{Submit your next manuscript to BioMed Central} and take full advantage of:

- Convenient online submission

- Thorough peer review

- No space constraints or color figure charges

- Immediate publication on acceptance

- Inclusion in PubMed, CAS, Scopus and Google Scholar

- Research which is freely available for redistribution

Submit your manuscript at www.biomedcentral.com/submit
C Biomed Central 